\title{
Drought in the U.S. Caribbean: Impacts on Livestock
}

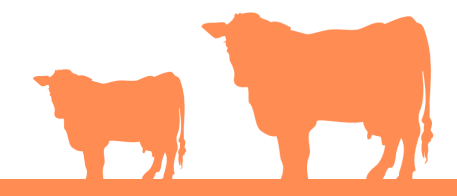

Authors: Eva Holupchinski, Nora Álvarez-Berríos, William Gould, and Josh Fain (USDA Caribbean Climate Hub, USFS)

Graphic: Integration \& Application Network, University of Maryland Center for Environmental Science

The production of dairy and beef is important for food security and the economies of the U.S. Caribbean. The dairy industry is the leading agricultural sector in Puerto Rico, contributing about $22 \%$ of the total agricultural income. Region-wide, beef and dairy production generate over 25,000 jobs and occupy more than 50,000 acres. In the U.S. Virgin Islands, cattle production has been declining in recent years due to higher insurance costs and natural disasters, while sheep and goat production has increased.

Caribbean countries are particularly vulnerable to climate change due to their geography and economic capacity. Climate change is driving temperatures higher and the region is experiencing more frequent and intense drought conditions. This affects livestock by decreasing water and feed availability, increasing susceptibility to worms and ticks, provoking heat stress, and reducing milk production.

\section{About this Series}

This fact sheet is part of a series examining what we know about the impacts of drought on ecosystems and agriculture in the U.S.

Caribbean. Explore the other fact sheets on:

- Coastal Estuary Ecosystems

- Freshwater Ecosystems

Tropical Forest Ecosystems

- Crops

View the complete series here: usgs.gov/casc/lslandDrought

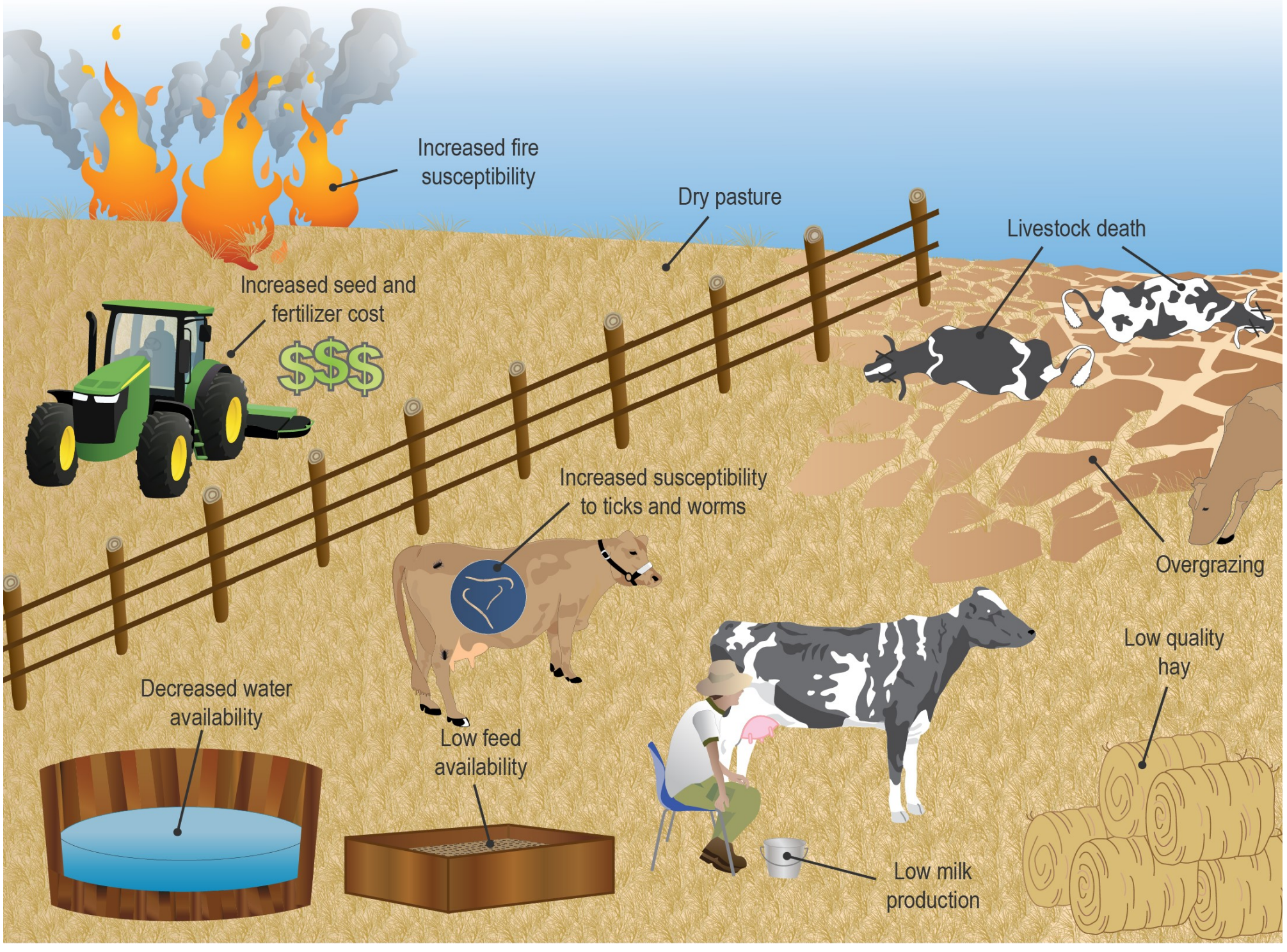




\section{Short-Term Impacts}

\section{Long-Term Impacts}

Dry Pastures: Dry pastures lead to lower quality hay and increased fire danger.

- Decreased Production: Heat stress can decrease milk production in dairy cattle and lower quality in beef.

Overgrazing: Decreases in feed availability can lead to overgrazing.
- Reduced Range Quality: Nutrient poor, drought-tolerant grass species may spread, decreasing range quality.

- Increased Costs: Production costs rise as farmers rely more heavily on imported feed and need to re-sow overgrazed pastures.

- Hay Shortages: Decreased water availability can lead to hay shortages.

\section{Spatial Impacts}

In Puerto Rico, livestock and dairy production are most common in the municipalities of Hatillo, Yabucoa, Camuy, Arecibo, Naguabo, San Sebastián, Lajas, Humacao, and Isabela. In 2015, two of the most heavily drought-impacted crops in Puerto Rico were grass and fodder, both essential for livestock nutrition.

In the USVI, livestock production is most common on St. Croix. In the summer of 2015, intense heat and lack of rain dried up ponds and grasses, forcing producers to collect palm fronds and tree branches for fodder, depend on expensive imported feed, and cull herds.

\section{Cross-Sector Impacts}

Economic: The impacts of drought on livestock can have consequences for the local economy. Lack of available feed during periods of drought forces livestock and dairy producers to purchase expensive concentrate feed, resulting in higher-priced meat and dairy products. Higher pricing makes it more difficult for local producers to compete with imported meat and dairy products.

Environmental: Drought-stricken rangelands are more prone to wildfire, soil compaction, increased water runoff which decreases groundwater recharge, and increased flooding during storms.

\section{Current Activities \& Future Research Directions}

The USDA Natural Resource Conservation Service (NRCS) is helping producers in the region mitigate the effects of drought through the Environmental Quality Incentives Program (EQIP). NRCS recommended practices include proper irrigation management for efficient water use and higher yields, rotational grazing for pasture maintenance, and the establishment of water sources for livestock such as ponds, wells and springs. Heat stress can also be limited by adding shade to farms and selecting varieties of drought and heat-resistant pasture, forage, and livestock species such as star grass and the "bald" Puerto Rican cow (Slick-haired Holstein).

- Research is needed to identify strategies that optimize livestock productivity while using fewer resources. During periods of drought, increased efficiency in feeding and nutrition strategies can bolster dairy and beef production while generating less carbon dioxide and methane.

\section{About Us}

This fact sheet is a product of the 2018 U.S. Caribbean Drought Workshop, hosted by the USDA Caribbean Climate Hub in collaboration with the Climate Adaptation Science Center (CASC) network. View a more detailed description of drought impacts on livestock at usgs.gov/casc/lslandDrought

CASCs: Delivering science to help fish, wildlife, water, land, and people adapt to a changing climate. Learn more: usgs.gov/casc Caribbean Climate Hub: Developing and delivering climate adaptation information. Find resources and tools at caribbeanclimatehub.org and climatehubs.oce.usda.gov/hubs/caribbean. International Institute of Tropical Forestry, Río Piedras, Puerto Rico. The USDA is an equal opportunity provider, employer and lender. 